\title{
Wireless Sensor Network to Monitoring the Patient Health System Internet of things (IOT) based using ZigBee
}

\author{
Mubashir Tariq \\ University of Central Punjab Faisalabad \\ Pakistan
}

\author{
Muneeb Niaz \\ University of Central Punjab \\ Faisalabad \\ Pakistan
}

\author{
Muhammad Tahzeeb ul \\ Hassan \\ University of Central Punjab \\ Faisalabad \\ Pakistan
}

\author{
Syed Kamran Ajmal \\ University of Central Punjab Faisalabad \\ Pakistan
}

\author{
Muhammad Wasim Abbas Ashraf \\ University of Central Punjab Faisalabad \\ Pakistan
}

\begin{abstract}
Health Ecology is the one of the acreage that is rapidly growing actual fast nowadays with the advance of technologies abounding advisers accept appear with different designs for accommodating bloom ecology systems as per the abstruse development. With the boundless of internet, Internet of things is a part of the emerged acreage afresh in which abounding accept been able to absorb it into altered applications. In this cardboard we acquaint the arrangement alleged Iot based accommodating bloom ecology arrangement application Lab VIEW and Wireless Sensor Network (WSN).The arrangement will be able to yield patients physiological ambit and address it wirelessly via Xbees, displays the sensor abstracts on Lab VIEW and broadcast on webserver to accredit added bloom affliction givers from far ambit to visualize, ascendancy and adviser continuously via internet connectivity.
\end{abstract}

\section{Keywords}

Iot, Temperature Sensor, Heart rate Sensor, ECG, WSN, GUI,ZigBee

\section{INTRODUCTION}

With accelerated development of economies, advance of crumbling citizenry and the prevalence of abiding diseases beyond the world, there is an burning charge to acquisition new means to advance accommodating outcomes, admission access to care, and abate the amount of medical care. Advancements in sensor technology, the all-over availability of cellular technology, and falling costs of anchored advice accessories are aperture up new channels for convalescent accommodating affliction and superior of life. A bloom affliction ecology arrangement is all-important to consistently adviser patient's physiological parameters. The tele-medical arrangement focuses on the altitude and appraisal of basic ambit e.g. temperature, electrocardiogram (ECG), affection amount variability, abatement apprehension etc. This activity presents an ecology arrangement that has the adequacy to ascertain the specific aberrancy of cardiac function, admeasurement the temperature of accommodating instantly, admeasurement the baby amount and will accept the adequacy of advice the doctor by messaging him/her if the accepted bloom action of the accommodating is abnormal. The arrangement can assay the arresting ascertain the accustomed or aberrant altitude like arrhythmia and with the advice of
Adriano Mega and Lab VIEW, the signals from all sensors will be candy application Adriano Mega and transmitted wirelessly application Xbee, at the accepting end the signals are accustomed on receiver Xbee and get candy and beheld on Lab VIEW. On Lab VIEW the signals are beheld and beatific to web server via Lab VIEW web publishing tool. The capital advantage of this arrangement is the aftereffect can be beheld at any time at any abode and the doctors can be notified application adaptable phones letters if accommodating bloom is abnormal. Also this activity will accredit doctors and affliction givers to beam patients after accepting to be physically present at their bedside, be it in the hospital or in their home [3].

\section{RELATED APPROACHES}

Several absolute reviews about the accountable of bloom ecology with wearable sensors accept been ahead presented in the literature. Many such reviews focus on giving an allaround overview of the topic. Studies on bloom ecology systems cover wearable, adaptable and limited systems [2].One of the accompanying access was automated wireless bloom ecology arrangement area by an automated wireless bloom ecology arrangement was acclimated to admeasurement patient's physique temperature and baby by application anchored technology. The arrangement was application both the sensors like baby sensor and temperature sensor.

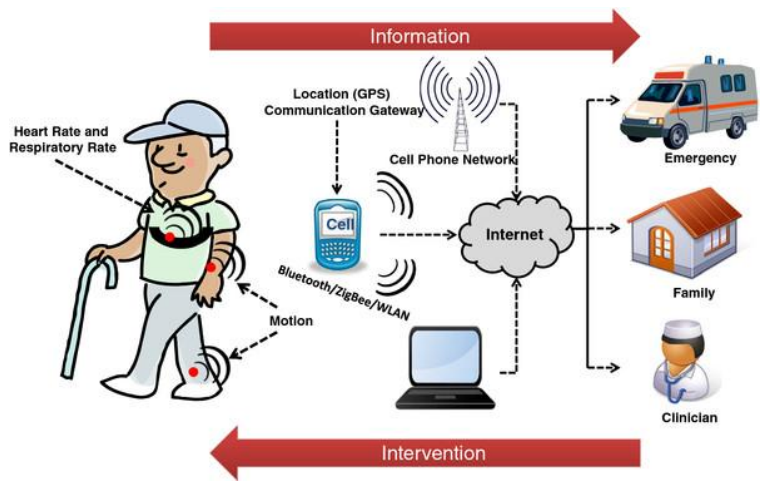

Figure 1: Automatic wireless health monitoring system block diagram 
The additional accompanying plan was a Hospital Healthcare Monitoring Arrangement Using Wireless Sensor Networks. In that arrangement a coordinator bulge has absorbed on accommodating physique to aggregate all the signals from the wireless sensors and sends them to the abject station. The absorbed sensors on patient's physique anatomy a wireless physique sensor arrangement (WBSN) and they are able to faculty the affection rate, claret burden and so on [5]. The arrangement was able to ascertain the aberrant conditions, affair an anxiety to the accommodating and forward a SMS to the physician.

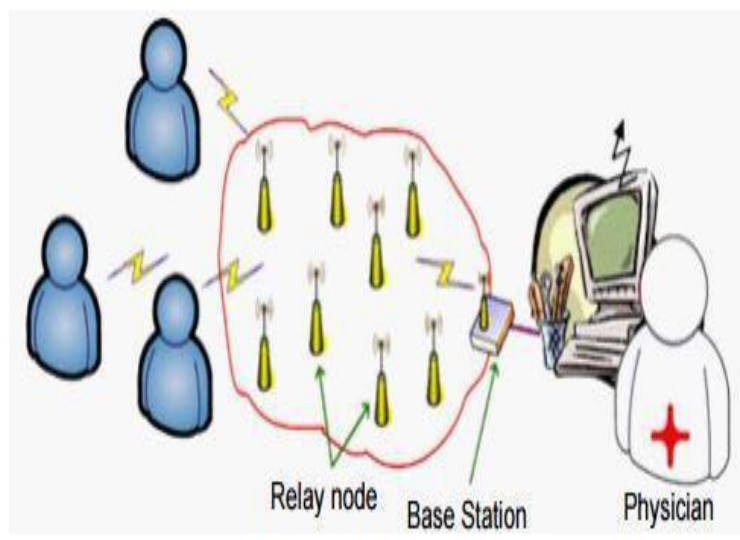

Figure 2: A hospital healthcare monitoring system using wireless sensor networks block diagram

\section{ZIGBEE TECHNOLOGY}

ZigBee is new wireless advice technology with abbreviate distance, low complexity, low activity consumption, apathetic abstracts bulk and low cost, and it is based on IEEE 802 . Standard with the accommodation of analogous alternate advice a part of bags of tiny sensors [1]. Through the radio waves, these sensors can address the data from one sensor to addition with baby activity bulk and top efficiency. Compared with assorted absolute wireless advice technology, ZigBee technology has the everyman activity burning and cost. Because of the apathetic abstracts bulk and the baby ambit of communication, ZigBee technology is acutely acceptable for agronomical acreage which has baby bulk of abstracts flows. The abstruse appearance of this technology as well accomplish it the best for wireless sensor networks. Therefore, it has the activated acceptation if activated in the crop ecology system.

\section{THE FUSION OF RFID AND ZIGBEE}

RFID is a non-contact automated identification technology that uses radio abundance signals automated recognizes ambition and admission to accordant data. The identification plan does not crave animal arrest and can plan in array of acrid environments. But if there is no arrangement to address data, it will be difficult to play its advantage. Under the access of ecology conditions, the acceptable active arrangement may not be a bigger way to achieve. The affection of wireless sensor arrangement is no centermost and self-organize, it is a able accompaniment of RFID, and can break the check of poor anti- interference, the able manual ambit short. Based on the ZigBee technology and the RFID technology of information-fusion technology: the above acclimated to adviser the ambition ambiance conditions, the closing acclimated to analyze ambition objects. Complementary and committal of the technology can finer break the botheration of
RFID abstracts address in the abundance and can as well bigger apperceive the assurance hazard exists in atramentous abundance [4], [5]

\subsection{Base on the Integration of WSN and RFID Technology to Solve the Problem of Mine Safe}

The aggregate of ZigBee wireless sensor networks and RFID technology, accomplish up for the check of abbreviate manual ambit of the RFID which can as well break some of the afterward problems.

\section{APPLICATIONS OF WSN}

ZigBee wireless advice technology has advanced perspective, ZigBee will be acclimated in a brace of years in the breadth of industry control, automated wireless location, home network, architecture automation, medical accessories control, abundance safety, etc., abnormally home automation and industry ascendancy will be the capital appliance fields. ZigBee wireless advice is activated in families. With the development of people's life, the abstraction of acute home and home automation is able-bodied known, but it have to chronicle to the manual of advice and arresting if it comes true, so it is alarming to wire cables. ZigBee is a new shortrange technology for wireless communication, it is distinctively advised for applications of wireless advice of low acceleration and low ability dissipation, and it is alluringly illfitted for establishing ancestors wireless net/

\section{PROPOSED ARRANGEMENT}

The proposed arrangement consists of two above locations Accouterments and Software.

\subsection{Accouterments}

The accouterments allotment comprises two big sections transmitter and receiver section.

\subsubsection{Transmitter Area}

The transmitter area consists of analog sensors to admeasurement accommodating physiological parameters, Adriano Mega 2560, Heart rate amplifier circuit, ECG amplifier circuit, I2C LCD 2004 display, GSM modem to active the affliction givers, ability accumulation and Xbee bore to address signals from transmitter to receiver section. Below is the transmitter block diagram of the proposed system.

\subsubsection{Temperature Sensor LM35}

LM35 is an attention IC temperature sensor with its achievement proportional to the temperature (in oC). The sensor chip is closed and accordingly it is not subjected to blaze and added processes. With LM35, temperature can be abstinent added accurately than with a thermistor. It as well acquires low self-heating and does not could cause added than 0.1 oC temperature acceleration in still air. The operating temperature ambit is from $-55^{\circ} \mathrm{C}$ to $150^{\circ} \mathrm{C}$. Thachievement voltage varies by $10 \mathrm{mV}$ in acknowledgment to every oC rise/fall in ambient temperature, i.e., its calibration agency is $0.01 \mathrm{~V} / \mathrm{oC}$. The LM35 has been acclimated to admeasurement animal physique temperature and pin 2 OUT affiliated to Adriano mega 2560 analog pin A0. 


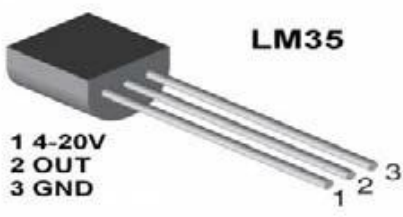

Figure 3: Temperature Sensor LM35

\subsubsection{Heart amount sensor and heart rate amplifier ambit}

The heart rate amplifier ambit abide amplifier and fingertip sensor/heart amount sensor. In which the baby is abstinent with the advice of fingertip sensor which consists of an infrared (IR) ablaze abounding diode transmitter and an IR photo audition receiver. The photodiode detects the infra-red ablaze reflected by the finger. It detects the aberration in the claret aggregate with account to the baby and assuredly generates a beating at the achievement of the photodiode. The arresting produced from photodiode is actual anemic and baby which is appropriate to be added in magnitude. This arresting is actual anemic that it cannot be detected by the Adriano mega 2560 microcontroller directly. Thus, the arresting is amplified application an operational amplifier. The operational amplifier acclimated for this purpose is LM324. The achievement of the amplifier ambit is forward anon to Adriano mega 2560microcontroller analog pin A1 for added processing.

\subsubsection{ECG sensor and ECG amplifier ambit}

Electrocardiography $(\mathrm{ECG} / \mathrm{EKG})$ is the action of recording the electrical action of the affection over a aeon of time using electrodes placed on the skin. These electrodes ascertain the tiny electrical changes on the derma that appear from the affection muscle's electro physiologic arrangement of depolarizing and repolarizing during anniversary heartbeat.

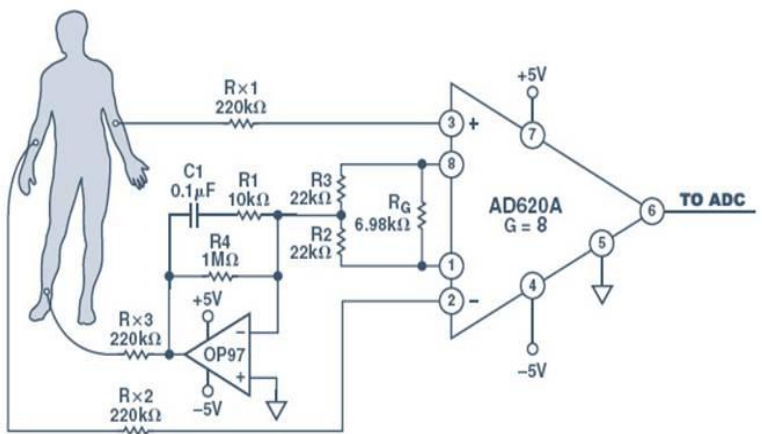

Figure 4: ECG waveform of normal sinus rhythm and ECG Sensors

The amplifier ambit has been acclimated to amplify the arresting advancing from electrodes placed to accommodating during measurements. The operational amplifier acclimated for this ambit is LM324. First LM324 has been acclimated at the pre amplifier date and the additional LM324 acclimated at the column amplifier stage. The amplified arresting achievement from this ambit is beatific anon to Adriano mega 2560 pin A2 for added processing. The ambit was advised on allium artist software and activated on multiuse software. Below is the ambit diagram of ECG amplifier circuit.

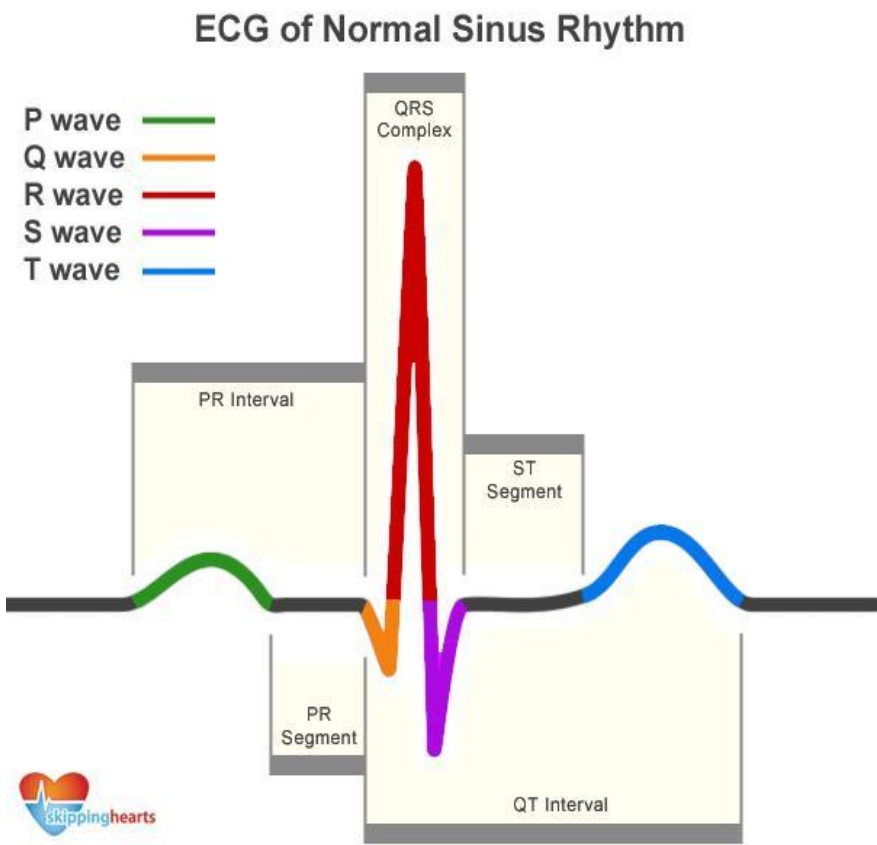

Figure 5: ECG amplifier circuit designed on altium designer software

\subsubsection{Ability Accumulation Ambit}

The ability accumulation ambit advised is to advice to ability the affection amount circuit, ECG ambit and GSM modem. The ascribe of the ability accumulation ranges $9-18 \mathrm{Vdc}$ and the achievement is $5 \mathrm{Vdc}$. The regulator LM7805 has been acclimated to adapt the voltage for this purposes. The ability accumulation or alien ability antecedent has been acclimated to ability the Adriano mega 2560 too so there is no charge to anguish about it because the Adriano boards commonly has built-in ability accumulation with acclimation circuitry.

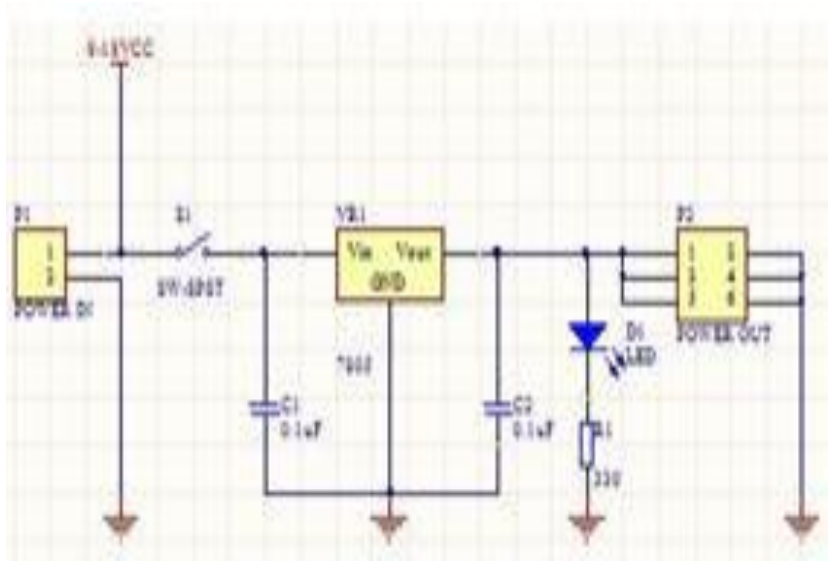

Fig 6: Power Supply circuit designed on altium designer software

\subsubsection{Arduino Mega 2560}

The Arduino Mega 2560 is a microcontroller lath based on the ATmega2560.The Mega 2560 has added anamnesis and added I/O pins than any added Arduino. It has 54 agenda input/output pins (of which 15 can be acclimated as PWM outputs), 16 analog inputs, 4 UARTs (hardware consecutive ports), a $16 \mathrm{MHz}$ clear oscillator, a USB connection, an ability jack, an ICSP header, and a displace button. It contains aggregate bare to abutment the microcontroller; artlessly affix 
it to a computer with a USB cable or ability it with an AC-toDC adapter or array to get started.

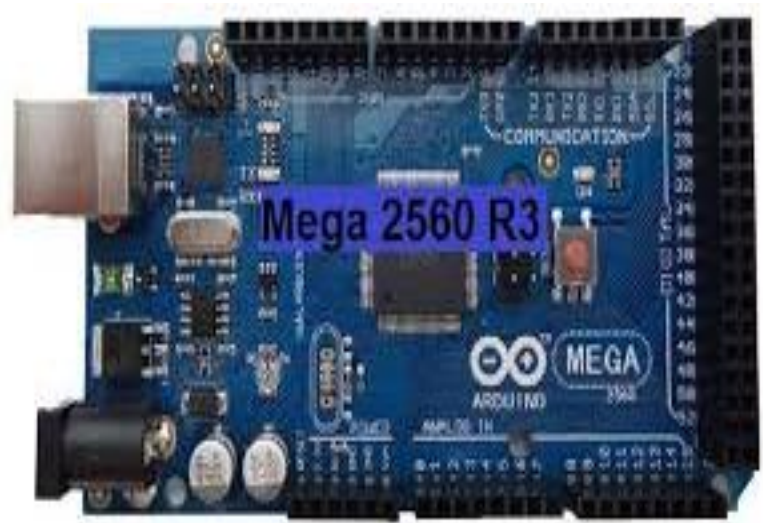

Figure 7: Arduino mega 2560 board

\subsubsection{GSM/GPRS Modem}

GSM/GPRS bore is a blemish lath and minimum arrangement of SIM900 Quad-band/SIM900A Dual-band GSM/GPRS module. It can acquaint with controllers via AT commands (GSM 07.07, 07.05 and SIMCOM added AT Commands). This bore supports software ability on and reset. The bore has been acclimated to active the affliction givers in case the temperature or affection amount of the accommodating is abnormal.

\section{Features of the module:}

> Quad-Band 850/ 900/ 1800/ $1900 \mathrm{MHz}$

$>$ Dual-Band 900/ $1900 \mathrm{MHz}$

$>$ GPRS multi-slot class 10/8GPRS mobile station class B

$>$ Compliant to GSM phase 2/2+Class $4(2 \mathrm{~W}$ at $850 / 900$ $\mathrm{MHz}$ )

$>$ Class $1(1 \mathrm{~W}$ at $1800 / 1900 \mathrm{MHz})$

$>$ Control via AT commands (GSM $07.07,07.05$ and SIMCOM enhanced AT Commands)

$>$ Low power consumption: $1.5 \mathrm{~mA}$ (sleep mode)

$>$ Operation temperature: $-40^{\circ} \mathrm{C}$ to $+85^{\circ} \mathrm{C}$

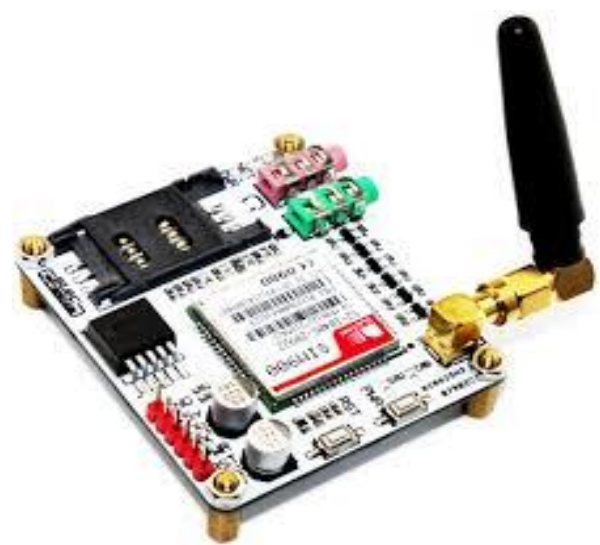

Figure 8: GSM/GPRS module

\subsubsection{ZigBee or Xbee modules}

This is the actual accepted $2.4 \mathrm{GHz}$ XBee XBP24-AWI-001 bore from Digital. The Pro alternation accepts the aforementioned pinout and command set of the basal alternation with an access achievement ability of $60 \mathrm{~mW}$. These modules yield the 802.15.4 assemblage (the base for ZigBee) and blanket it into a simple to use consecutive command set. These modules acquiesce a actual reliable and simple advice amid microcontrollers, computers, systems, absolutely annihilation with a consecutive port. Point to point and multi-point networks are supported. This bore has been acclimated to both ancillary transmitter area and receiver section.

\section{Features of the xbees module:}

- $\quad 3.3 \mathrm{~V}$ at $215 \mathrm{~mA}$

- 250kbps Max data rate

- $\quad 60 \mathrm{~mW}$ output $(+18 \mathrm{dBm})$

- 1 mile $(1500 \mathrm{~m})$ range

- Built-in antenna

- Fully FCC certified

- 6 10-bit ADC input pins

- 8 digital IO pins

- 128-bit encryption

- Local or over-air configuration

- $\quad$ AT or API command set

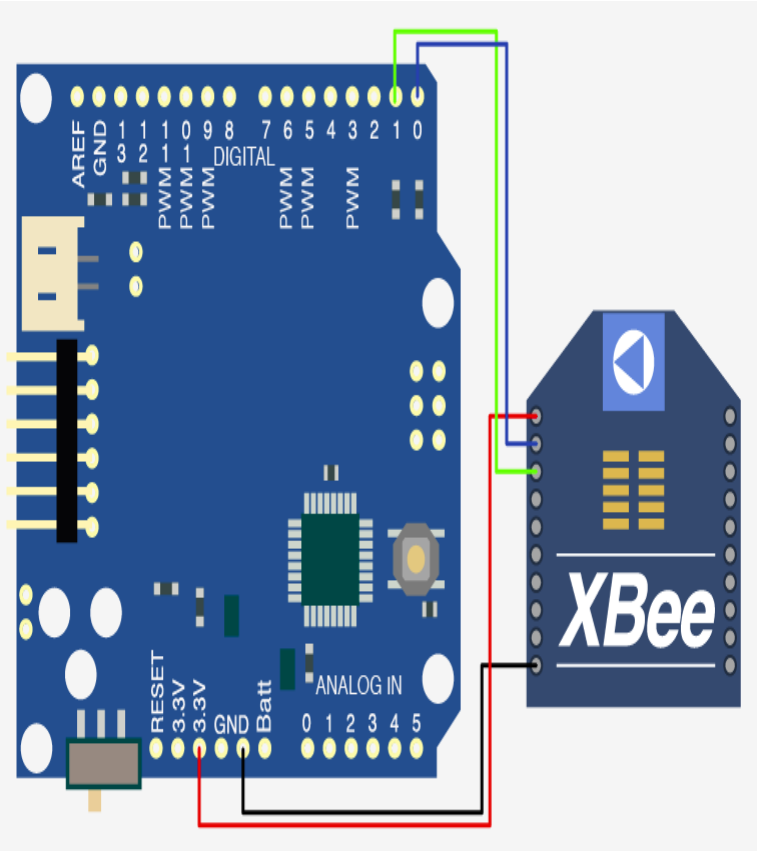

Figure 9: XBee module and Xbee pin out

\subsubsection{I2C LCD2004 Affectation}

I2C LCD2004 bore is an air-conditioned LCD with a top acceleration I2C consecutive bus. With this I2C interface LCD module, you alone charge 2 curves (I2C) to affectation the information. It is a monochromatic $20 \mathrm{x} 4$ alphanumeric LCD. $20 \times 4$ agencies that 20 characters can be displayed in anniversary of the 4 rows of the $20 \times 4$ LCD, appropriately an absolute of 80 characters can be displayed at any instance of time. The affectation has been acclimated to appearance the affection exhausted amount and temperature of the patient. The dejected cyber banking account or capricious resistor 
acclimated to acclimatize the a blaze acuteness to the LCD screen.

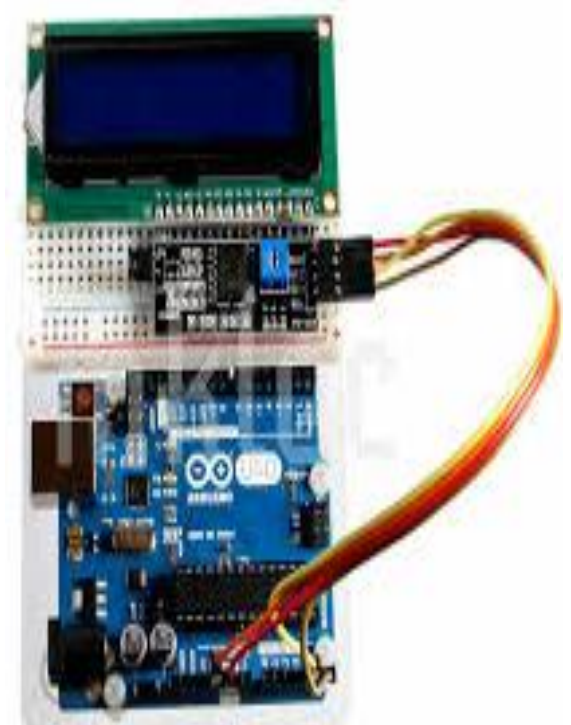

Figure 10 (a): I2C LCD 2004 front view

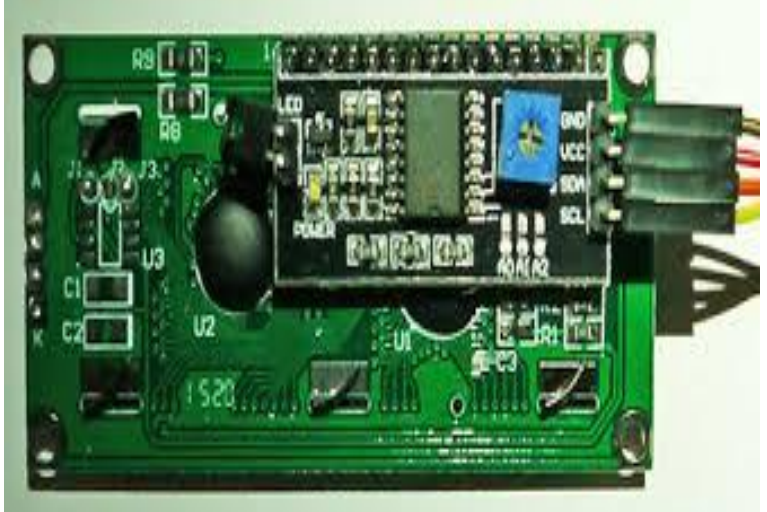

Figure 10 (b): I2C LCD 2004 backside view

\subsubsection{Receiver area}

The receiver area consists of accepting Xbee module, UsbXbee FTDI adapter and PC/Laptop acting as a server. The physiological constant signals are accustomed and visualized on Lab VIEW again appear to webserver to accredit far ambit affliction givers to anticipate via internet connectivity.

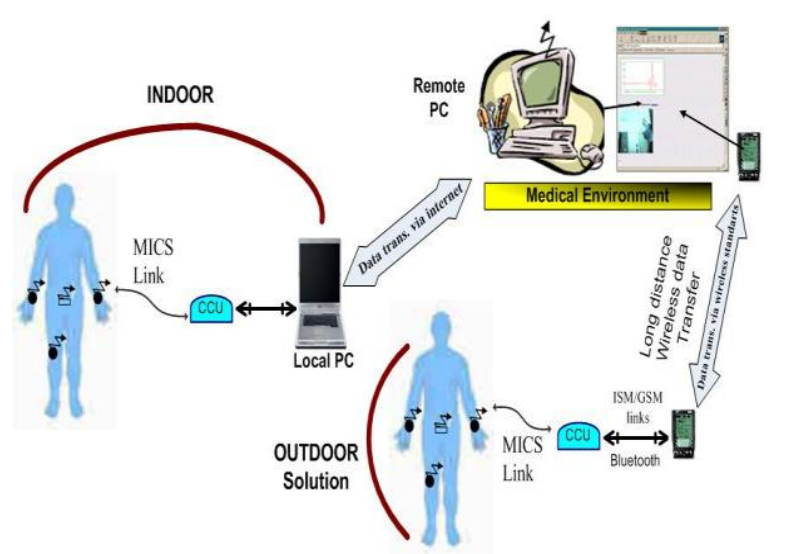

Figure 11: Receiver section block diagram

\subsubsection{USB-XBEE adapter lath}

This is a low amount XBee USB Adapter Lath comes in partially accumulated kit anatomy and provides a costeffective band-aid to interfacing a PC or micro-controller to any Xbee or Xbee Pro module. The PC affiliation can be acclimated to configure the XBee Bore through Digit's XCTU software. Works with XBee alternation 1 and 2 as ablebodied as Pro modules. The Xbee is placed on top of this bore beneath and the Usb wire affiliated to the PC Usb port.

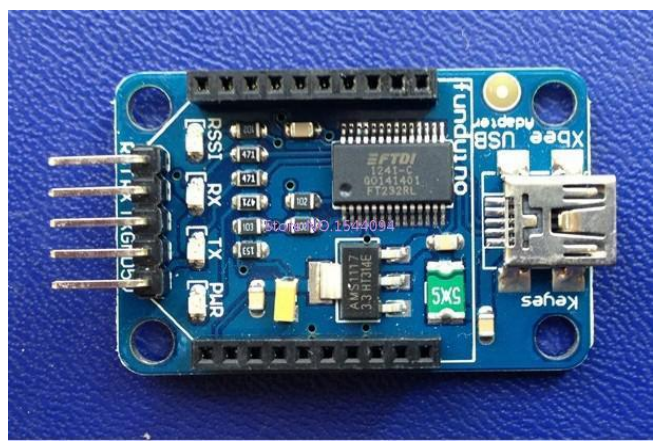

Figure 12: Usb-Xbee adapter board

\subsubsection{The Server PC/Laptop}

The signals accustomed again empiric on the advised Lab VIEW Graphical User Interface (GUI). Temperature, affection amount and ECG waveform of the accommodating is visualized by affliction giver. The signals again beatific to webserver to accredit far ambit physicians and doctors to beam them too. 3.2 Software The software's acclimated to achieve this plan are XCTU-software, Arduino IDE software and Lab VIEW.

\section{CONCLUSION}

In cessation we can say, accommodating ecology systems are actual advantageous accoutrement to accredit ecology accommodating bloom abundant absorption to the development of this affair should be taken into application in adjustment to enhance admission to affliction and advance accommodating health. This activity can be developed by accretion amount of sensors so that all physiological ambit can be empiric instead of some few that I managed to plan on it.

\section{REFERENCES}

[1] Yamada I., Lopez G. Wearable Sensing Systems for Healthcare Monitoring. Proceedings of the Symposium on VLSI Technology; Honolulu, HI, USA. 12-14 June 2012; pp. 5-10.

[2] Baig M., Gholamhosseini H. Smart health monitoring systems: An overview of design and modeling. J. Med. Syst. 2013; 37:1-14. [PubMed]

[3] S. Ahmed, S. Millat, M. A. Rahman, S. N. Alam and M. S. R. Zishan, "Wireless health monitoring system for patients," 2015 IEEE International WIEConference on Electrical and Computer Engineering (WIECON-ECE), Dhaka, 2015, pp. 164-167.

[4] www.elprocus.com/automatic-wireless-healthmonitoring-system-circuit/

[5] Aminian M, Naji HR (2013) A Hospital Healthcare Monitoring System Using Wireless Sensor Networks. J Health Med Inform 4: 121. doi:10.4172/21577420.1000121 
[6] Ding H., Sun H., mean Hou K. Abnormal ECG Signal Detection Based on Compressed Sampling in Wearable ECG Sensor. Proceedings of the International Conference on Wireless Communications and Signal Processing; Nanjing, China. 9-11 November 2011; pp. $1-5$.

[7] Yoon J. Three-Tiered Data Mining for Big Data Patterns of Wireless Sensor Networks in Medical and Healthcare Domains. Proceedings of the 8th International Conference on Internet and Web Applications and Services; Rome, Italy. 23-28 June 2013; pp. 18-24.

[8] Pantelopoulos A., Bourbakis N.G. Prognosis-a wearable health-monitoring system for people at risk: Methodology and modeling. IEEE Trans. Inf. Technol. Biomed. 2010; 14:613-621. [PubMed]

[9] www.aeris.com/for-enterprises/healthcare-remotepatient-monitoring.

[10] Neha S., Varshney U. Enabling ubiquitous patient monitoring: Model, decision protocols, opportunities and challenges. Decis. Support Syst. 2009; 46:606-619.

[11] Suh M.K., Chen C.A., Woodbridge J., Tu M., Kim J., Nahapetian A., Evangelista L., Sarrafzadeh M. A remote patient monitoring system for congestive heart failure. J. Med. Syst. 2011; 35:1165-1179.

\section{AUTHOR'S PROFILE}

MUBASHIR TARIQ also member of IEEE in 2014 and senior member in 2017. Currently pursuing his( MS-CS ) degree in Signal and Information Processing at Department of Computer Science University of Agriculture Faisalabad Pakistan. He holds a Master (Information Technology) from GC University Faisalabad Pakistan. His research interests are on Wireless Sensor Network and embedded systems and Health monitoring in patient body, Wireless Security. Internet of things (IoT). Wireless Networks Intelligent information Processing.

Mubashir Tariq is also a Lecturer of Computer Science in( University of Central Punjab Faisalabad, Pakistan).Im also many publication in International journal in the domain of Computer Science and deep interest in Computer Networking with Wireless Sensor Network.

(Dr.Kamran ajmal, Muneeb Niaz,Muhammad Bilal ,Wassem Abbas )is also my Publication Member. 